\title{
Reverse Bite and Dislocation: A Study on the Communication of Yu Hua's To Live by We Media
}

\author{
Qingqing Yu*
}

Zhejiang A \& F University, Hangzhou 311300, China. E-mail: 2834216638@qq.com

\begin{abstract}
Based on the amount of readers' reading and clicks, the power of article creation of We Media has shifted significantly from author to reader, the market mechanism formed by the readers' preferences bite the author's creation space. Taking Yu Hua's To Live as an example to analyze We-Media writings, it can be found that the confidence of the novel text and Yu Hua's image have been obviously misplaced, and the space of creation and communication has been reversed. In the form of quotations for the public through consumption experience, the original text is cut and stitched together to becomes the chicken soup for the soul in the late night, and Yu Hua is portrayed as a "punster". It is undeniable that the communication of works by We Media has the advantages that traditional media cannot reach. The techniques and social relations that We Media communication relies on are worthy of the development of traditional media.

Keywords: Yu Hua's To Live; We Media; Aesthetics of Reception; Communication Studies
\end{abstract}

\section{The dislocation of the text information and writer's image}

In the process of We Media writing creation, the reader mode of material grafting can lead to the dislocation of the To Live text information and the image of the writer Yu Hua. The author of We Media articles ignores the specific context to quote. He or she lists and assembles the sentence elements from the novel, or quotes the original text of the novel in a curt way, resulting in the disconnection between the quoted content and the narrative point of view, the misplacement of the meaning of the novel text and the passive misreading of the readers. The author deconstructs the image of Yu Hua in order to gain more clicks, which leads to the misplacement of the image of the writer.

In Aesthetics of Reception, Iser proposes that "the reader of ideas" "[1] contains the reader of image objects. The reader of the image object, that is, the reader who is necessary for the writer to understand the work and create the reality of the image. In the process of creating a novel about Yu Hua's life, the author of the novel designs the readers who have finished the novel reading in advance. Such as "have you read To Live, but you don't know the miracle of it", the author assumes that the reader has completed novel, on the basis of reading activities, to convey positive impact of the To Live for people and society. For those who have no previous reading experience, they can only get partial information about To Live. It is easy to create a narrow stereotypes and biased understanding of the novel, leading to the misreading and dislocation of To Live the original meaning.

Using the "material grafting model" to shape Yu Hua into a spiritual teacher of life and a "punster" would result in the dislocation of the image of the writer. In view of readers' emotional confusion and difficulty in life, the author of We Media articles makes positive creations by quoting a large number of famous quotes from Yu Hua's novels. The author quotes "a man should never forget-never err in speech, never err in bed, never step on the wrong threshold,

Copyright (C) 2020 Qingqing Yu

doi: $10.18686 / \mathrm{mcs} . \mathrm{v} 2 \mathrm{i} 3.1329$

This is an open-access article distributed under the terms of the Creative Commons Attribution Non-Commercial License

(http://creativecommons.org/licenses/by-nc/4.0/), which permits unrestricted non-commercial use, distribution, and reproduction in any medium,

provided the original work is properly cited. 
never touch the wrong pocket" ${ }^{\text {"2] }}$, to pass on the principles to the readers by Yu Hua. In the "The jokes/Yu Hua, To Live, is a collection of jokes", the classic sentences in To Live are extracted and illustrated with illustrations by Weibo author, Peep Show. He makes jokes about life through the way of mutual interpretation of words and pictures. Yu Hua is portrayed as a "punster".

The author abandons the original context to quotate rigidly, resulting in the incoherent logic of the language and the unnatural transition between different contents. Pure sentence display would be difficult for readers to understand the deep meaning of some expressions in the novels. The actual information conveyed by We Media articles is not equal to To Live, the image created by We Media articles is also not consistent with the writer himself, and the literary connotation of We Media articles is reduced to the surface work under the guise of the writer.

\section{Adaptation bite create and spread space}

It is the strong reader centrality that is embodied by We Media article. The market influences the content creation, production and communication mode of web articles, and readers' reading experience and feedback influence or decide the fate of web articles. Jauss, reader-centered theory ${ }^{[3]}$, has been strongly confirmed in the course of We Media articles. Guided by readers' reading needs and measured by clicks and reads, the form of works can be shaped according to readers' market, which is bound to reverse the creation space and communication space to some extent.

On the one hand, the excessive pursuit of the reader's market leads to the negative impact on the creation space. Jauss had ever advocated the reader-centered theory in the aesthetics of reception, that is, even if a work has been printed and published, it is still a semi-finished work without the participation of readers before they read it. However, We Media follows the logic of readers' market and puts readers' functions before creation. The limitations of readers lead to the negative impact on the communication space of We Media articles. On the "read at 10 p.m." WeChat platform, We Media articles are keen to cater to the psychology of the audience and solve the current life problems. Therefore, they pay special attention to the shallow excavation and secular application of the suffering thought of To Live. This kind of articles do provide readers with practical and convenient methods to solve the problems in secular life, but the author's creation space is also limited due to readers' reading preferences.

Catering to the reader market leads to a fact that We Media articles of communication space was attacked. Statistically, Weibo and WeChat are the mainly social platforms with the largest number of users in China. The articles based on the "social relationship resources" ${ }^{[4]}$ of Weibo and WeChat is "linked" through with friends-sharing and group-pushing, which makes the readers on the We Media platform more customer loyalty, resulting in the over-reliance on social relations for the spread of articles. The information transmission amplifies the Bandwagon Effect - if an article is forwarded by a certain consistent group, it can form a popularity of reading online articles in a short time. Hot articles come into being. As the popularity continues to rise, readers' reading choice is also influenced by the Bandwagon Effect to a greater extent. Under the influence of this, high-quality but not yet hot clicks can only be hidden, thus forming "the strong is stronger, the weak is weaker" Matthew Effect transmission phenomenon.

The accurate grasp of readers' reading preferences and the precise selection of the target audience to the article on the We-Media platform prompt the author to create articles in line with the reader's market. Readers' reading activities and the creative behaviors of the platform authors have jointly contributed to the reading culture circle on WeChat platform. The stable supply-demand relationships, between the author and the readers and the push from We Media platform, have enabled the works to spread rapidly in the circle. There are no audients and communications channels for such articles outside the circle, so it is difficult for the articles to spread effectively beyond the circle, thus limiting the space of article dissemination.

\section{The way of presentation bites the space of creation and communication}

There are significant differences between literary creations in the context of "We Media" and traditional literary creation. Compared with the traditional literary writers represented by Yu Hua, the creation concept of web writers on a 
We-Media platform represented by Weibo and WeChat has changed. In their creation, web writers adopt a narrative method that is more suitable for We Media writing, network communication, mobile phone reading, shallow reading and fragmented reading. The We Media platform has limitations on the length of online works, and readers' reading preferences and knowledge level have self limitations, which inevitably urges the creators of online works to adopt the text presentation methods that are easy for readers to accept, such as chicken soup, jokes and quotations.

The way of We Media writing bites the author's creation space. Due to the limitation of space and reading environment, the narrative structure of We Media cannot adhere to the integrity and stability of the structure like the recommended subjects (To Live by Yu Hua). Instead, the content of We Media is arranged in a short presentation mode suitable for mobile terminal reading, such as chicken soup prose, jokes and quotations. In the form of chicken soup, quotations, and jokes, the short subject is secularized. Although it satisfies the readers' experience of mobile phone reading and shallow reading, the limited text and secularized subject cannot make the We Media writers present the rich connotation of Yu Hua's To Live in their creation.

The way of presenting network text causes the space of communication to be attacked. Melvin DE fleur, the American communicator, in Mass Communication Theory, believes that the audience has personal differences in information acceptance, and the audience's interests and hobbies need values and attitudes, which affect the audience's avoidance and rejection of information acceptance ${ }^{[5]}$. On the one hand, online readers read selectively according to their own interests, hobbies and values; on the other hand, they actively avoid the unattractive presentation to them. For example, some readers with lower cognitive ability but higher emotional sensitivity tend to read chicken soup. Readers with higher cognitive ability, cultural level and critical thinking ability tend to read argumentative articles. Readers with a strong sense of purpose are fond of reading Weibo jokes. Readers, as the audiences of the articles information, have the personality of receiving them. The personality of different readers even determines whether or not they read and how much they read. Therefore, different ways of presenting articles are favored by their respective reader groups, and it is difficult for readers to communicate with each other. As a result, some types of articles can only be spread among their respective reader groups ${ }^{[6,7]}$.

\section{Conclusion}

With the application of advanced Internet technologies on We-Media platforms, on the one hand, real-time interaction between creators and readers has been realized, which helps creators accurately and timely understand the expectations of readers and grasp the direction of online writing. On the other hand, something behind the mechanism of readers' influence on the creation and dissemination of We Media articles is the scene where the current social culture evolves towards the form of reader-centered theory of Jauss under the influence of consumption and experiential reading behavior. The influence of the receivers on the creation of literary works increases, and the power in the mechanism of literary creation shifts from the author to the reader, thus breaking the original balance of the mechanism of literary creation. In an unbalanced state, the creation of We Media articles is easy to reflect the phenomenon that the writers and their works are mismatched to promote, which ignores the objectivity and authenticity ${ }^{[8,9]}$.

In the era of We Media, the double superposition of knowledge and market mechanism makes the production and creation of We Media literature have to pay more attention to the needs and feedback of readers. On the We Media platform, the modes of communication are mainly social interpersonal relationship and circle interaction ${ }^{[10]}$. The surface media of communication behavior is the "We Media" platform, while the deep media is individual. For traditional media, it is a good beginning for them to see the essence behind the phenomenon and actively think about the corresponding countermeasures.

\section{References}

1. Jauss HR, Hollab RC. Receptional aesthetics and receptional theory (in Chinese). Zhou N, Jin Y (translators). Shenyang: Liaoning People's Publishing House; 1987. 
2. Zhu L. Introduction to receptional aesthetics (in Chinese). Hefei: Anhui Education Press; 2004.

3. Tong Q. Literary theory course (in Chinese). Beijing: Higher Education Press; 2005.

4. Qiu D. Anti-bite and misalignment: Self-media network articles to promote Yang Jiang and his works (in Chinese). New Media Research 2019; 5(4): 7-8+22.

5. Max W. Economy and society (Volume 1) (in Chinese). Yan K (translator). Shanghai: Shanghai Renmin Chubanshe; 2010. p. 134.

6. Defleur ML, Ball-Rokeach S. Introduction to mass communication (in Chinese). Du L (translator). Beijing: Xinhua Publishing House; 1990. p. 200.

7. Ouyang Y. The existence mode and functional orientation of WeChat literature (in Chinese). Jianghai Academic Journal 2015; (1): 195-200.

8. Chen L. Forwarding, interactive writing and the reconstruction of "Discussing Community" in social media space. Journal of International Communication 2015; 37(10): 6-17.

9. Yu H. To Live. Shanghai: Shanghai Literature and Art Publishing House; 2005. p. 7.

10. Li S. Subject turning and text presentation from self-media culture (in Chinese). Studies in Culture Art 2018; 11(4): 7-12. 